\title{
Regulation of Human Eosinophil Degranulation and Activation by Endogenous Phospholipase $A_{2}$
}

Steven R. White, Mary E. Strek, Giorgio V. P. Kulp, Stephen M. Spaethe, ${ }^{\star}$ Robbi A. Burch, Scott P. Neeley, and Alan R. Leff Section of Pulmonary and Critical Care Medicine, Department of Medicine and the Committees on Clinical Pharmacology and Cell Physiology, The Division of Biological Sciences, University of Chicago, Chicago, Illinois 60637; and the *Pulmonary Research Division, Lilly Research Laboratories, Indianapolis, Indiana 46265

\begin{abstract}
The unique granular proteins of eosinophils may have a pathogenetic role in asthma and in the defense against parasitic infestations. However, the mechanisms regulating eosinophil degranulation are largely unknown. We examined the hypothesis that release of these proteins is regulated by endogenous activation of phospholipase $A_{2}$. Human eosinophils (HE) were isolated from the peripheral blood of $\mathbf{4 2}$ subjects either by Percoll density separation or by negative-selection immunomagnetic fractionation. Eosinophil activation was initiated in vitro with $10^{-6} \mathrm{M}$ FMLP and $5 \mu \mathrm{g} / \mathrm{ml}$ cytochalasin B and was assessed by measurement of eosinophil peroxidase (EPO), leukotriene $\mathrm{C}_{4}\left(\mathrm{LTC}_{4}\right)$ and superoxide radical $\left({ }^{\circ} \mathrm{O}_{2}^{-}\right)$secretion. Treatment of $\mathrm{HE}$ with $100 \mu \mathrm{M}$ mepacrine before activation blocked EPO release $(2.0 \pm 0.2$ vs $10.2 \pm 2.1 \%$ cell content for activated $H E, P$ $<0.004, n=9),{ }^{\circ} \mathrm{O}_{2}^{-}$generation (2.6 \pm 0.9 vs $44.2 \pm 10.8 \mathrm{nmol} /$ $\mathrm{ml}$ per $10^{6} \mathrm{HE}, P<0.002, n=5$ ), and $\mathrm{LTC}_{4}$ secretion (68.2 \pm 32.2 vs $1,125.2 \pm 526.8 \mathrm{pg} / \mathrm{ml}$ per $10^{6} \mathrm{HE}, P<0.04, n$ $=8$ ). Pretreatment of $\mathrm{HE}$ with $100 \mu \mathrm{M}$ 4-bromophenacyl bromide before activation similarly blocked EPO release, ${ }^{\circ} \mathrm{O}_{2}^{-}$generation and $\mathrm{LTC}_{4}$ secretion. Addition of $\mathrm{AA}$ to $\mathrm{HE}$ after treatment with $100 \mu \mathrm{M}$ mepacrine and before subsequent activation reversed the inhibition of both $\mathrm{EPO}(10.4 \pm 2.2 \%$ with $1 \mu \mathrm{MAA}$ vs $2.0 \pm 0.2 \%$ for mepacrine, $n=5, P<0.02)$ and LTC $_{4}$ secretion (695.1 \pm 412.9 with $10 \mu \mathrm{M}$ AA vs $68.2 \pm 32.2 \mathrm{pg} / \mathrm{ml}$ per $10^{6}$ HE for mepacrine, $n=8, P<0.04$ ), but did not reverse inhibition of ${ }^{\circ} \mathrm{O}_{2}^{-}$generation by mepacrine. We demonstrate that secretion of preformed cytotoxic proteins and ${ }^{\circ} \mathrm{O}_{2}^{-}$by eosinophils is regulated endogenously by phospholipase $A_{2}$. ( J. Clin. Invest. 1993.91:2118-2125.) Key words: eosinophils • phospholipase $A_{2} \cdot$ eosinophil peroxidase $\bullet$ leukotrienes $\bullet$ mepacrine
\end{abstract}

\section{Introduction}

Human eosinophils may have a prominent role in the defense against parasitic infection and in the alterations of airway function in asthma (1). Eosinophil infiltration of airways is a characteristic feature of asthma, and the presence of blood, bronchoalveolar lavage fluid, and tissue eosinophilia correlates to

This work was presented in part at the annual meeting of the American Thoracic Society, Miami Beach, FL, 20 May 1992.

Address correspondence to Steven R. White, M. D., Section of Pulmonary and Critical Care Medicine, The University of Chicago, 5841 S. Maryland Avenue, MC 6076, Chicago, IL 60637.

Received for publication 12 May 1992 and in revised form 21 December 1992.

J. Clin. Invest.

(c) The American Society for Clinical Investigation, Inc. $0021-9738 / 93 / 05 / 2118 / 08 \quad \$ 2.00$

Volume 91, May 1993, 2118-2125 the severity of the disease (2-5). Eosinophil activation and secretion of both lipid and protein inflammatory mediators, such as platelet-activating factor $(6)$, leukotriene $\mathrm{C}_{4}\left(\mathrm{LTC}_{4}\right)^{1}$ $(7,8)$, major basic protein $(9,10)$, eosinophil cationic protein (11), eosinophil-derived neurotoxin (11), and eosinophil peroxidase (EPO) $(11,12)$, have profound effects on the structure and function of airway cells, including the alteration of airway smooth muscle tone and damage to airway epithelial cells. However, the mechanisms by which eosinophils degranulate and release preformed protein mediators into the external environment has not been defined completely.

Phospholipase $\mathrm{A}_{2}$ (EC3:1.1.4, PLA $\mathrm{A}_{2}$ ), a lipolytic enzyme that catalyzes the hydrolysis of a glycerol phosphatide to yield a lysophosphatide and AA, is an ubiquitous enzyme that exists in both cell membranes (13) and lysosomes $(14,15)$. Recently, $\mathrm{PLA}_{2}$ release from eosinophils has been described in association with release of cationic protein granules from eosinophils (16), suggesting that this enzyme may be a part of either the granular matrix or the membrane of the granule. However, the function of $\mathrm{PLA}_{2}$ in the granule is unknown, and the role of this enzyme in the regulation of eosinophil degranulation has not been defined.

The objective of this study was to determine if inhibition of endogenous eosinophil PLA $\mathrm{PL}_{2}$ alters the release of granular protein mediators from activated eosinophils. We used two different inhibitors of $\mathrm{PLA}_{2}$ function: mepacrine, which forms stable complexes of drug and phospholipid substrate $(17,18)$, or 4bromophenacyl bromide (BPB), which modifies an active site histidine residue in $\mathrm{PLA}_{2}$ (19). We isolated eosinophils from peripheral blood of normal volunteers and determined EPO release, $\mathrm{LTC}_{4}$ secretion and superoxide radical $\left({ }^{\circ} \mathrm{O}_{2}^{-}\right)$generation after incubation with either mepacrine or BPB. We demon-

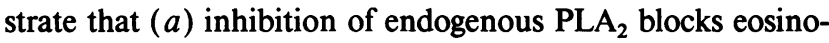
phil degranulation and release of EPO, secretion of $\mathrm{LTC}_{4}$, generation of ${ }^{\circ} \mathrm{O}_{2}^{-}$, and $(b)$ addition of exogenous $\mathrm{AA}$, a principal product of the hydrolytic reaction catalyzed by $\mathrm{PLA}_{2}$, reverses the inhibition of eosinophil degranulation and secretion of $\mathrm{LTC}_{4}$, suggesting that both processes may be dependent upon endogenous AA generated by PLA $A_{2}$. These data suggest a mechanism by which products of $\mathrm{PLA}_{2}$ may regulate degranulation and secretion of inflammatory mediators in human eosinophils.

\section{Methods}

Isolation of human eosinophils. Human eosinophils were isolated from volunteers according to a protocol approved by the University of Chi-

1. Abbreviations used in this paper: BPB, 4-bromophenacyl bromide; CYB, cytochalasin B; EPO, eosinophil peroxidase; GEL, $0.1 \%$ gelatin in HBSS containing $1 \mathrm{mmol} /$ liter $\mathrm{Ca}^{2+} ; \mathrm{LTC}_{4}$, leukotriene $\mathrm{C}_{4}$; $\mathrm{PLA}_{2}$, phospholipase $\mathrm{A}_{2}$. 
cago Institutional Review Board. Informed consent was obtained from all volunteers in this study before participation. To ensure that the method of isolation was not a factor in these experiments, two different isolation methods were used.

In the first method, eosinophils were isolated by density fractionation centrifugation $(20,21)$. Whole blood $(180 \mathrm{ml})$ was withdrawn from the antecubital vein of 17 human volunteers and placed into containers containing $2 \mathrm{ml}$ of $1: 1,000$ heparin. Blood then was mixed $5: 1$ with $4.5 \%$ dextran in $0.9 \% \mathrm{NaCl}$ and sedimented for $45 \mathrm{~min}$ at $22^{\circ} \mathrm{C}$. The white blood cell layer was collected, divided into $30-\mathrm{ml}$ aliquots, and layered over $10 \mathrm{ml}$ Ficoll-Hypaque (density $1.077 \mathrm{~g} / \mathrm{ml}$ ) in $50-\mathrm{ml}$ tubes. Cells then were centrifuged at $400 \mathrm{~g}$ for $20 \mathrm{~min}$ (all centrifugations done at $22^{\circ} \mathrm{C}$ ). The pellet containing leukocytes was resuspended in $\mathrm{Ca}^{2+}$-free $\mathrm{HBSS}$ and twice washed and centrifugated at $400 \mathrm{~g}$ for $10 \mathrm{~min}$. Cells then were suspended in HBSS containing 1 $\mathrm{mmol} /$ liter $\mathrm{Ca}^{2+}$ and 5\% FCS and diluted to a concentration of 2 $\times 10^{7} / \mathrm{ml}$. In separate $15-\mathrm{ml}$ tubes discontinuous Percoll gradients were prepared (from top to bottom in $\mathrm{g} / \mathrm{ml} \mathrm{[ml]:} 1.080$ [2.5]; 1.085 [2.5]; 1.090 [3.0]; 1.095 [3.0]; 1.100 [1.5], prepared in HBSS), over which $2 \mathrm{ml}$ of cell suspension was layered. Gradients then were centrifuged at $700 \mathrm{~g}$ for $20 \mathrm{~min}$. The interface containing eosinophils (1.095$1.100 \mathrm{~g} / \mathrm{ml}$ ) was collected, diluted in $0.1 \%$ gelatin in HBSS containing $1 \mathrm{mmol} /$ liter $\mathrm{Ca}^{2+}$ (GEL) and then centrifuged at $400 \mathrm{~g}$ for $10 \mathrm{~min}$. Eosinophils then were washed, centrifugated at $400 \mathrm{~g}$ for $10 \mathrm{~min}$ and resuspended in GEL. Eosinophils were counted and assessed for purity by Wright stain. Eosinophils were kept on ice until use and used within $1 \mathrm{~h}$ of final purification to prevent deterioration.

In the second method, eosinophils were isolated by negative-selection immunomagnetic fractionation using an antibody to CD16, a $\mathrm{FcR}_{\mathrm{III}}$ receptor found on neutrophils but not eosinophils (22). In 22 additional human volunteers, $60-120 \mathrm{ml}$ whole blood was withdrawn from the antecubital vein and placed into containers containing $2 \mathrm{ml}$ of 1:1,000 heparin. Blood was diluted 1:1 with $\mathrm{Ca}^{2+}$-free HBSS, layered over $15 \mathrm{ml}$ of $1.083 \mathrm{~g} / \mathrm{ml}$ Percoll and centrifugated for $30 \mathrm{~min}$ at $900 \mathrm{~g}$ (all centrifugations done at $4^{\circ} \mathrm{C}$ ). Cells then were diluted 1:4 with an erythrocyte-lysing solution containing $155 \mathrm{mM} \mathrm{NH}_{4} \mathrm{Cl}, 10 \mathrm{mM}$ $\mathrm{KHCO}$, and $0.1 \mathrm{mM}$ EDTA for $15 \mathrm{~min}$. The remaining granulocytes were centrifugated for $10 \mathrm{~min}$ at $400 \mathrm{~g}$ and resuspended in $25 \mu \mathrm{l}$ of $2 \%$ FCS in $\mathrm{Ca}^{2+}$-free HBSS; $75 \mu$ l of anti-human CD-16 monoclonal antibody bound to $0.1-\mu \mathrm{m}$ magnetic beads (Miltenyi Biotec $\mathrm{GmbH}$, Bergisch-Gladbach, Federal Republic of Germany) then was added. Granulocytes were incubated at $4^{\circ} \mathrm{C}$ for $45 \mathrm{~min}$ and then resuspended in 4 $\mathrm{ml}$ of $2 \% \mathrm{FCS}$ in $\mathrm{Ca}^{2+}$-free HBSS. Granulocytes then were passed through a $1 \times 10 \mathrm{~cm}$ column packed with steel wool and held within a 0.6 Tesla MACS magnet (Becton Dickinson, Mountain View, CA) over $30 \mathrm{~min}$. Neutrophils binding the antibody-magnetic bead were retained in the magnetized steel wool, while eosinophils passing through the column were collected, washed, and resuspended in GEL. Counts and purity were assessed as above. Cells were kept on ice until use and used within $1 \mathrm{~h}$ of final purification as above.

Determination of eosinophil peroxidase concentrations in eosinophils and eosinophil-conditioned media. The EPO concentration in cells and conditioned media was measured as the velocity of maximal reaction of oxidation of $o$-phenylenediamine using a kinetic assay that we have developed previously for these studies (20). Eosinophil cell suspensions, eosinophil-conditioned medium, and purified EPO ( $\mathrm{mol}$ wt $\sim 70,000$ ) were suspended in GEL and frozen at $-70^{\circ} \mathrm{C}$ until immediately before use. For the assay, $50 \mu \mathrm{l}$ of sample or EPO standard were combined with $75 \mu$ l of substrate (final concentrations: $0.01 \%$ hydrogen peroxide, $6 \mathrm{mM} o$-phenylenediamine, and $0.06 \%$ Triton X-100 dissolved in $60 \mathrm{mM}$ Tris, $\mathrm{pH} \mathrm{8.0)}$ ) in a polystyrene 96-well microplate and placed into a thermoregulating microplate absorbance spectrophotometer (Thermomax; Molecular Devices Corp., Menlo Park, CA) at $37^{\circ} \mathrm{C}$. Absorbance at $492 \mathrm{~nm}$ was measured every $6 \mathrm{~s}$ for $3 \mathrm{~min}$; the maximal velocity of the reaction was calculated by interpolation between successive three points ( $18 \mathrm{~s}$ ) using customized software (Softmax v2.01; Molecular Devices Corp.) on a Macintosh computer, and compared to EPO standards generated at the same time. Standards were assayed in triplicate; suspended cell and conditioned media samples were assayed in duplicate. Eosinophil cell suspensions were diluted 1:4 with HBSS containing $1 \mathrm{mmol} /$ liter $\mathrm{Ca}^{2+}$ immediately before assay. Final EPO concentrations then were calculated from standard curves fitted by four-parameter (iterative log-logit) analysis, and expressed finally as percent total EPO content of the eosinophils (me$\operatorname{dium} /[$ medium + cell pellet $]$ ) in conditioned media (20).

Determination of $\mathrm{LTC}_{4}$ concentrations in eosinophil-conditioned media by enzyme-linked immunosorbent assay. This technique offers exceptional sensitivity $\left(<20 \mathrm{pg} / \mathrm{ml}\right.$ at $\left.80 \% \mathrm{~B} / \mathrm{B}_{0}\right)$ and specificity $(46 \%$ cross-reactivity with leukotriene $\mathrm{D}_{4}$ and $<2 \%$ cross-reactivity for other leukotrienes) in biologic fluids. This assay is particularly suitable for these studies because eosinophils do not synthesize leukotriene $D_{4}(23$, 24). Microplates were prepared by coating with mouse monoclonal anti-rabbit IgG (Cayman Chemical Co. Inc., Ann Arbor, MI) in phosphate buffer and incubated for $18 \mathrm{~h}$ at $20^{\circ} \mathrm{C}$. Plates then were saturated with buffer $(300 \mathrm{mg} /$ liter sodium azide and $3 \mathrm{~g} /$ liter BSA in phosphate buffer) for $18 \mathrm{~h}$ at $4^{\circ} \mathrm{C} .50 \mu \mathrm{l}$ of either standard or sample was added to each well, followed by $50 \mu \mathrm{l}$ of $\mathrm{LTC}_{4}$-specific acetylcholinesterase tracer

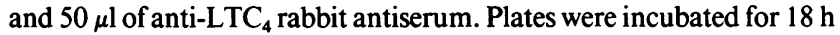
at $22^{\circ} \mathrm{C}$, rinsed with buffer five to six times, and developed with $200 \mu \mathrm{l}$ Ellman's reagent $\left(14.6 \mathrm{mM} \mathrm{NaCl}, 12.5 \mathrm{mM} \mathrm{K}_{2} \mathrm{HPO}_{4}, 0.5 \mathrm{mM}\right.$ acetylthiocholine, and $300 \mathrm{mg} /$ liter 5,5'-dithio-bis-[2-nitrobenzoic acid] in $\mathrm{H}_{2} \mathrm{O}$ at $\mathrm{pH} 7.4$ ) as substrate. Absorbance was measured with a microplate spectrophotometer at $412 \mathrm{~nm}$ and compared to a standard curve generated at the same time on the same plate. All measurements were made in duplicate.

Determination of eosinophil viability after inhibition of phospholipase $A_{2}$ with mepacrine or $B P B$. To determine if either mepacrine or BPB decreased eosinophil viability, trypan blue exclusion was determined in eosinophils incubated with either inhibitor. Aliquots of $10^{5}$ eosinophils isolated by immunomagnetic fractionation were incubated for $30 \mathrm{~min}$ at $37^{\circ} \mathrm{C}$ in microfuge tubes containing $0,1,3,10,30,100$, or $300 \mu \mathrm{M}$ mepacrine ( $n=5$, isolated by percoll separation) or BPB ( $n$ $=3$, isolated by magnetic fractionation ) in GEL. Eosinophils then were centrifugated at $400 \mathrm{~g}$ and pellets were resuspended in $200 \mu \mathrm{l} \mathrm{GEL}$. An equal volume of $0.01 \%$ trypan blue was added, and viable eosinophils were counted in a hemacytometer.

Determination of eosinophil release of EPO after inhibition of phospholipase $A_{2}$. In these experiments, EPO secretion in stimulated eosinophils after PLA $\mathrm{P}_{2}$ inhibition was measured. Aliquots of $5 \times 10^{5}$ eosinophils isolated by percoll separation from 11 donors were incubated in separate microfuge tubes containing $3,10,30,100$, or $300 \mu \mathrm{M}$ mepacrine, or $1,3,10,30,100$, or $300 \mu \mathrm{M} \mathrm{BPB}$, in GEL for $30 \mathrm{~min}$ at $37^{\circ} \mathrm{C}$. Eosinophils then were activated with $10^{-6}$ M FMLP plus $5 \mu \mathrm{g} / \mathrm{ml}$ cytochalasin B (CYB) (final volume $200 \mu \mathrm{l}$ ) for $30 \mathrm{~min}$ at $37^{\circ} \mathrm{C}$ and then centrifugated at $4^{\circ} \mathrm{C}$ at $400 \mathrm{~g}$. Eosinophil pellets diluted to $1 \mathrm{ml}$ with GEL and conditioned medium (undiluted) were stored separately at $-70^{\circ} \mathrm{C}$ for determination of EPO concentrations. Separate control experiments were performed in the same manner for each experiment, in which eosinophils were pretreated with either $100 \mu \mathrm{M}$ mepacrine or $300 \mu \mathrm{M}$ BPB but not activated, or activated with FMLP and CYB but not pretreated with either PLA $_{2}$ antagonist.

Determination of eosinophil ${ }^{\bullet} \mathrm{O}_{2}^{-}$generation after inhibition of phospholipase $A_{2}$. In these experiments, ${ }^{\circ} \mathrm{O}_{2}^{-}$generation in stimulated eosinophils after PLA $\mathrm{PL}_{2}$ inhibition was measured. The method of Pick and Mizel (25) as modified by Sedgwick et al. (21) was used for this assay. Aliquots of $10^{5}$ eosinophils were incubated for $30 \mathrm{~min}$ at $37^{\circ} \mathrm{C}$ in microplate wells containing $0,1,3,10,30,100$, or $300 \mu \mathrm{M}$ mepacrine $(n$ $=5$, isolated by percoll separation $)$ or $\mathrm{BPB}(n=5$, isolated by magnetic fractionation ), $100 \mu \mathrm{mol} /$ liter of cytochrome c, $10^{-6} \mathrm{M}$ FMLP and 5 $\mu \mathrm{g} / \mathrm{ml} \mathrm{CYB}$ in GEL (final volume of reaction, $200 \mu \mathrm{l}$ ). Absorbance at $550 \mathrm{~nm}$ was determined immediately and then every $5 \mathrm{~min}$ for $60 \mathrm{~min}$ in a microplate spectrophotometer. Identical control reactions were performed at the same time with the addition of $20 \mu \mathrm{g} / \mathrm{ml} \mathrm{SOD} \mathrm{to} \mathrm{each}$ well. ${ }^{\circ} \mathrm{O}_{2}^{-}$generation was calculated with an extinction coefficient of $21.1 \times 10^{3} \mathrm{~mol} \cdot$ liter $^{-1} \cdot \mathrm{cm}^{-1}(26)$ and expressed finally as the $\mathrm{nmol} /$ $\mathrm{ml}$ per $10^{6}$ eosinophils minus SOD control. 
A

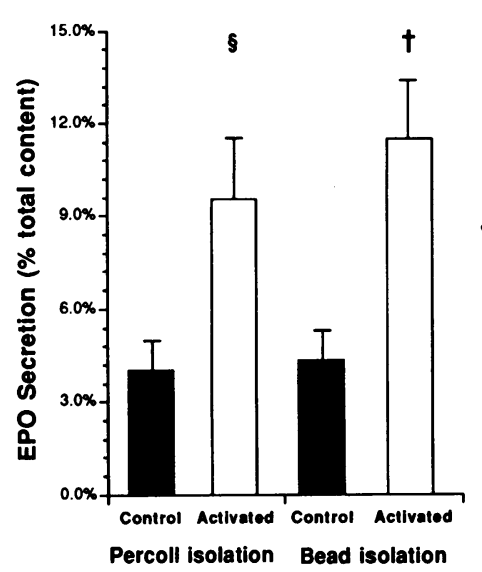

B

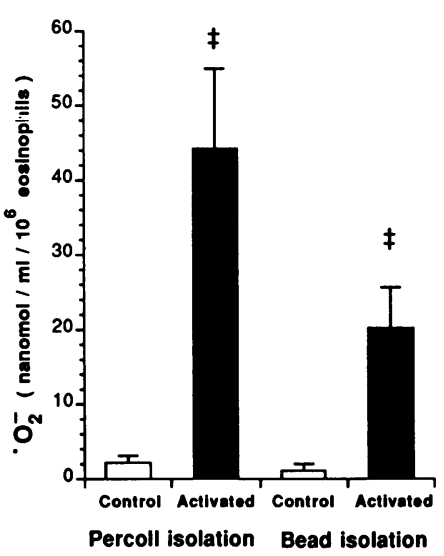

C

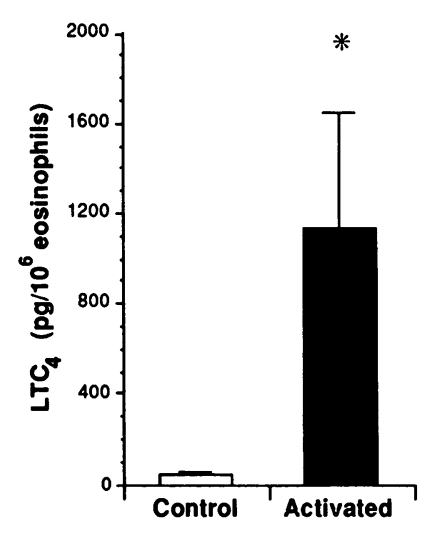

Figure 1. Activation of eosinophils by $n$-formyl-metleu-phe and cytochalasin B. Activation causes substantial release of $(A) \mathrm{EPO},(B)$ generation of ${ }^{\circ} \mathrm{O}_{2}^{-}$, and $(C)$ secretion of $\mathrm{LTC}_{4}$. Eosinophils were separated by immunomagnetic fractionation for (C) $(n=8)$, and both Percoll density separation and immunomagnetic fractionation for $(A)(n=11$ and 8 , respectively) and $(B)(n=5$ and 7 , respectively). ${ }^{*} P$ $<0.04 ;{ }^{\S} P<0.02 ;{ }^{\ddagger} P$ $<0.005{ }^{\dagger} P<0.002$ vs control.
Reversal of mepacrine-induced inhibition of EPO release, $L T C_{4}$ secretion and ${ }^{\circ} \mathrm{O}_{2}^{-}$generation by arachidonic acid. To determine the specificity of mepacrine in inhibiting eosinophil activation and degranulation, EPO release and $\mathrm{LTC}_{4}$ secretion were measured in activated eosinophils after incubation with AA. In 13 additional experiments, aliquots of $5 \times 10^{5}$ eosinophils isolated by immunomagnetic fractionation were incubated for $15 \mathrm{~min}$ at $37^{\circ} \mathrm{C}$ with $100 \mu \mathrm{M}$ mepacrine and then for an additional $15 \mathrm{~min}$ at $37^{\circ} \mathrm{C}$ with either 1 or $10 \mu \mathrm{M} \mathrm{AA}$ in GEL. Eosinophils then were incubated for $30 \mathrm{~min}$ at $37^{\circ} \mathrm{C}$ with $10^{-6} \mathrm{M}$ FMLP plus $5 \mu \mathrm{g} / \mathrm{ml}$ CYB (final volume $300 \mu \mathrm{l}$ ). Eosinophils were centrifugated at $400 \mathrm{~g}$ for $10 \mathrm{~min}$ at $4^{\circ} \mathrm{C}$, and both media and cell pellets were stored at $-70^{\circ} \mathrm{C}$ for analysis of either EPO ( $n=$ five experiments) or $\mathrm{LTC}_{4}$ ( $n=$ eight experiments) concentrations. Control experiments with either no mepacrine, no AA, or neither agent were done at the same time using identical numbers of eosinophils.

In three additional experiments the potential ability of AA to reverse the inhibition of ${ }^{\circ} \mathrm{O}_{2}^{-}$generation by mepacrine was tested. Eosinophils isolated by immunomagnetic fractionation were incubated in 100

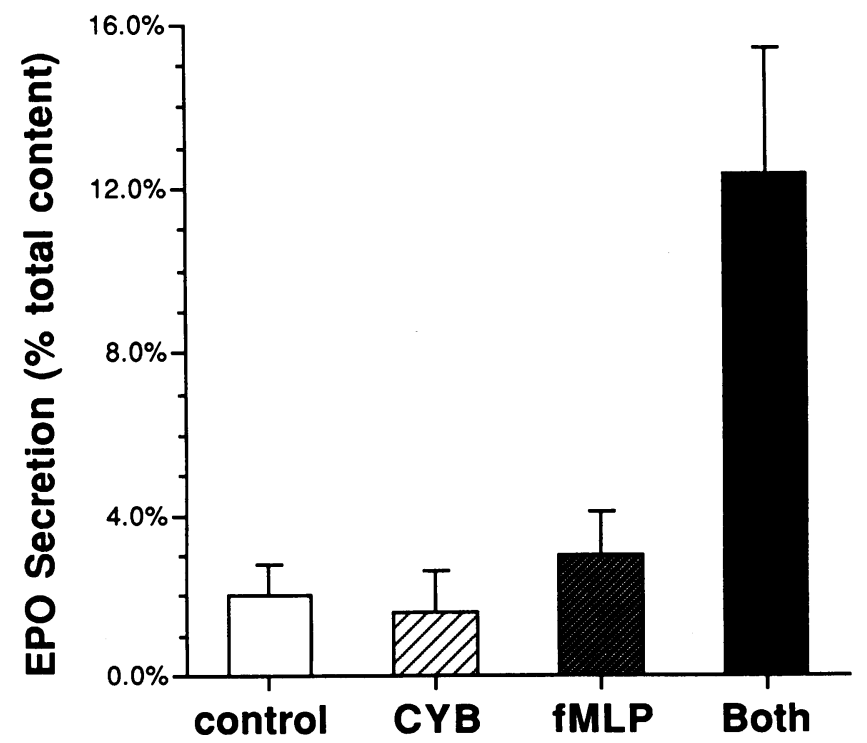

Figure 2. Eosinophil secretion of EPO $30 \mathrm{~min}$ after activation with either $5 \mu \mathrm{g} / \mathrm{ml}$ CYB alone, $10^{-6} \mathrm{M}$ FMLP alone, or the same concentrations of both CYB and FMLP ( $n=3$ for each). Neither CYB nor FMLP alone elicit significant EPO secretion compared to both FMLP + CYB together, or compared to control (neither FMLP nor CYB). Eosinophils were separated by immunomagnetic fractionation. $\mu \mathrm{M}$ mepacrine for $15 \mathrm{~min}$ followed by either 0,1 , or $10 \mu \mathrm{M}$ AA in GEL for an additional $15 \mathrm{~min}$ at $37^{\circ} \mathrm{C}$. Activation with FMLP and CYB, and measurement of ${ }^{\circ} \mathrm{O}_{2}^{-}$generation, were then done as above.

Materials. Percoll, Tris (as $99.9 \%$ Trisma base), Triton X-100, $\mathrm{H}_{2} \mathrm{O}_{2}$, o-phenylenediamine, cytochalasin-B, FMLP, superoxide dismutase, ferricytochrome c, arachidonic acid, and gelatin were obtained from Sigma Chemical Co., St. Louis, MO. Mepacrine and 4-bromophenacyl bromide were obtained from Lilly Research Laboratories, Indianapolis, IN. All reagents were molecular biology grade or higher. Purified EPO was a gift of Dr. Gerald J. Gleich, Mayo Clinic, Rochester, $\mathrm{MN}$, and was isolated from an eosinophil-rich suspension obtained by leukapheresis of patients with hypereosinophilic syndromes (27).

Data analysis. All data are expressed as mean \pm SEM. Comparisons of eosinophil secretion of EPO, $\mathrm{LTC}_{4}$, and ${ }^{\circ} \mathrm{O}_{2}^{-}$between several groups were made by repeated-measures analysis of variance. When significant differences were found, additional comparisons were made with Fisher's protected least significant difference test. Comparisons between two groups were made with Student's $t$ test; paired comparisons were made when appropriate. Due to the significance variance in secretion of $\mathrm{LTC}_{4}$ after activation, a normal distribution of $\mathrm{LTC}_{4}$ secretion was not assumed. Differences in $\mathrm{LTC}_{4}$ secretion between treatment groups were compared by the Friedman statistic. When significant differences were found, additional comparisons were made with the Wilcoxon signed-rank test. Corrections for multiple comparisons were made as necessary with the Bonferroni correction (28). Significance was claimed when $P<0.05$.

\section{Results}

Activation of human eosinophils. Isolation of eosinophils from peripheral blood by either centrifugation through discontinuous Percoll gradients or negative selection immunomagnetic fractionation yielded eosinophils of high purity ( $92.6 \pm 0.8 \%$ and $99.1 \pm 0.8 \%$, respectively). Stimulation of eosinophils with $10^{-6} \mathrm{M}$ FMLP and $5 \mu \mathrm{g} / \mathrm{ml} \mathrm{CYB}$ elicited release of EPO, secretion of $\mathrm{LTC}_{4}$, and generation of ${ }^{\circ} \mathrm{O}_{2}^{-}$in each experiment (Fig. 1). Treatment with $5 \mu \mathrm{g} / \mathrm{ml} \mathrm{CYB}$ alone in three additional experiments did not cause either secretion of EPO (Fig. 2) or generation of ${ }^{\circ} \mathrm{O}_{2}^{-}$(data not shown). Treatment with $10^{-6} \mathrm{M}$ FMLP alone in these experiments also did not cause eosinophil degranulation and release of EPO (Fig. 2).

There were no differences in the release of EPO in FMLPactivated eosinophils isolated by immunomagnetic fractionation compared to eosinophils isolated by Percoll density centrifugation. EPO release in eosinophils isolated by Percoll sepa- 
ration was $9.5 \pm 2.0 \%$ of total cell content; whereas EPO release in eosinophils isolated by immunomagnetic fractionation was $11.0 \pm 2.6 \%$ of total cell content $(P=0.48)$ (Fig. 1). Eosinophils isolated by immunomagnetic fractionation secreted less ${ }^{\circ} \mathrm{O}_{2}^{-}$ compared to eosinophils isolated by Percoll density centrifugation. Superoxide ion production stimulated by $10^{-6} \mathrm{M}$ FMLP and $5 \mu \mathrm{g} / \mathrm{ml}$ CYB in Percoll-isolated eosinophils was $44.2 \pm 10.8 \mathrm{nmol} / \mathrm{ml}$ per $10^{6}$ eosinophils in five experiments vs $20.4 \pm 5.2 \mathrm{nmol} / \mathrm{ml}$ per $10^{6}$ eosinophils for magnetic-isolated eosinophils in eight other experiments $(P=0.07)$. Because of potential differences in mediator secretion, the same isolation method was used throughout the series for each series of experiments.

Determination of eosinophil viability after incubation with mepacrine or $B P B$. Incubation of isolated eosinophils with either mepacrine or BPB in concentrations $\leq 100 \mu \mathrm{M}$ did not alter significantly the ability of eosinophils to exclude trypan blue. In five experiments using mepacrine, control eosinophils were $95.2 \pm 1.4 \%$ viable compared to $94.4 \pm 1.8 \%$ viability in eosinophils incubated for 30 min with $30 \mu \mathrm{M}$ mepacrine $(P$ $=$ NS). Viability was $>88 \%$ of control in eosinophils incubated with $100 \mu \mathrm{M}$ mepacrine. In three additional experiments using BPB, control eosinophils were $99.4 \pm 0.2 \%$ viable compared to $99.3 \pm 0.4 \%$ viability in eosinophils incubated for 30 min with $100 \mu \mathrm{M}$ BPB $(P=\mathrm{NS})$.

Inhibition of eosinophil release of EPO after inhibition of phospholipase $A_{2}$. Incubation with either mepacrine or BPB inhibited the subsequent activation of eosinophils by FMLP + CYB. Pretreatment with $100 \mu \mathrm{M}$ mepacrine decreased subsequent eosinophil release of EPO from $10.2 \pm 2.1 \%$ to $2.0 \pm 0.2 \%$ of total cell content $(P<0.004, n=$ nine experiments, Fig. 3). Pretreatment with $100 \mu \mathrm{M}$ BPB decreased subsequent eosinophil release of EPO from $9.4 \pm 2.6 \%$ to $2.5 \pm 0.8 \%$ of total cell content $(P<0.04, n=$ seven experiments, Fig. 4$)$. Inhibition of eosinophil degranulation was caused by preincubation with $\geq 3 \mu \mathrm{M}$ of either antagonist (Figs. 3 and 4 ).

Incubation of nonactivated eosinophils with either mepacrine or BPB did not alter the baseline release of EPO. Incubation of nonactivated eosinophils with $300 \mu \mathrm{M}$ mepacrine caused EPO release of $4.1 \pm 1.3 \%$ total cell content vs $4.8 \pm 1.0 \%$ total cell content for control eosinophils $(P=\mathrm{NS})$. Incubation of nonactivated eosinophils with $300 \mu \mathrm{M}$ BPB caused EPO

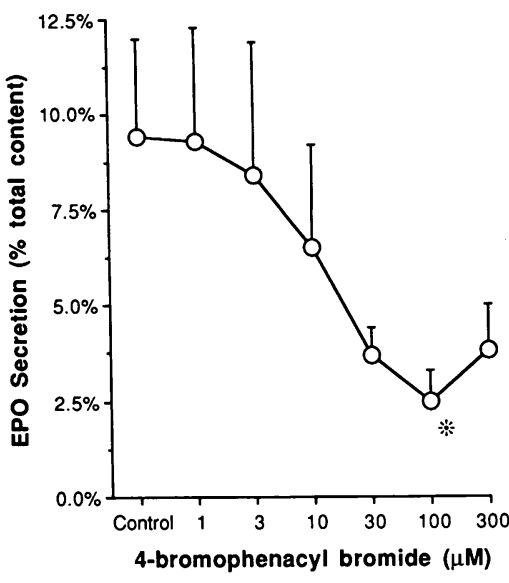

Figure 4. Eosinophil secretion of EPO after inhibition of phospholipase $\mathrm{A}_{2}$ by 4-bromophenacyl bromide. Incubation of human eosinophils $(n=$ seven experiments) with bromophenacyl bromide blocked the subsequent release of EPO after stimulation with FMLP and CYB. ${ }^{*} P<0.04$ vs control. Eosinophils were separated by Percoll density gradients.

release of $3.8 \pm 0.8 \%$ total cell content vs $4.4 \pm 1.2 \%$ total cell content for control eosinophils ( $P=\mathrm{NS}$ ).

Determination of eosinophil ${ }^{\bullet} \mathrm{O}_{2}^{-}$generation after inhibition of phospholipase $A_{2}$. Coincubation with mepacrine inhibited the generation of ${ }^{\circ} \mathrm{O}_{2}^{-}$in eosinophils activated with FMLP + CYB. In five experiments, treatment of eosinophils with 100 $\mu \mathrm{M}$ mepacrine during activation caused ${ }^{\circ} \mathrm{O}_{2}^{-}$generation of $1.9 \pm 0.9 \mathrm{nmol} / \mathrm{ml}$ per $10^{6}$ eosinophils after $30 \mathrm{~min}$ vs $44.2 \pm 10.8 \mathrm{nmol} / \mathrm{ml}$ per $10^{6}$ eosinophils for activated eosinophils not treated with mepacrine $(P<0.002)$ (Fig. 5). Superoxide radical generation was inhibited in eosinophils after incubation with all concentrations of mepacrine $\geq 1 \mu \mathrm{M}$ (Fig. 5 ). Mepacrine did not cause ${ }^{\circ} \mathrm{O}_{2}^{-}$generation in nonactivated eosinophils. After $30 \mathrm{~min}$, nonactivated eosinophils treated with 100 $\mu \mathrm{M}$ mepacrine generated ${ }^{\circ} \mathrm{O}_{2}^{-}$equal to $2.2 \pm 1.2 \mathrm{nmol} / \mathrm{ml}$ per $10^{6}$ eosinophils vs $0.1 \pm 0.7 \mathrm{nmol} / \mathrm{ml}$ per $10^{6}$ eosinophils for control $(P=\mathrm{NS})$.

Coincubation with BPB also inhibited the generation of ${ }^{\circ} \mathrm{O}_{2}^{-}$in eosinophils activated with FMLP + CYB. In five additional experiments, treatment of eosinophils with $100 \mu \mathrm{M}$ BPB during activation caused ${ }^{\circ} \mathrm{O}_{2}^{-}$generation of $1.2 \pm 0.5 \mathrm{nmol} / \mathrm{ml}$ per $10^{6}$ eosinophils after $30 \mathrm{~min}$ vs $26.3 \pm 5.2 \mathrm{nmol} / \mathrm{ml}$ per $10^{6}$ eosinophils for activated eosinophils not treated with BPB ( $P$ $<0.005$ ) (Fig. 6). Superoxide radical generation was inhibited in eosinophils after incubation with all concentrations of BPB $\geq 10 \mu \mathrm{M}$ (Fig. 6).

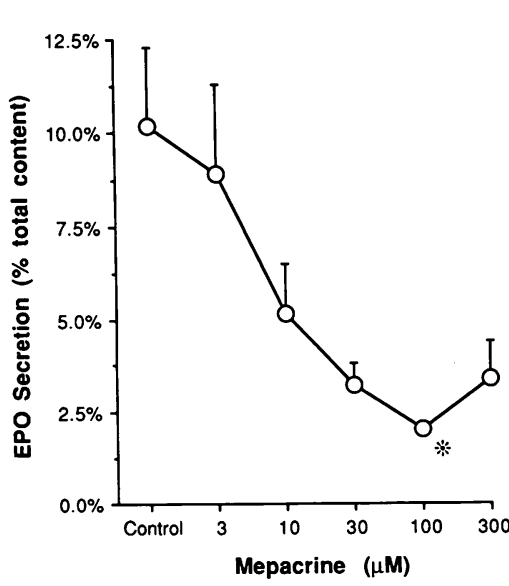

Figure 3. Eosinophil secretion of EPO after inhibition of phospholipase $A_{2}$ by mepacrine. Incubation of human eosinophils $(n=$ nine experiments) with mepacrine blocked the subsequent release of EPO after stimulation with FMLP and CYB. ${ }^{*} P<0.004$ vs control. Some standard error bars are contained within the point symbols. Comparison is made at $100 \mu \mathrm{M}$ mepa-

crine, the point of maximal inhibition, in these and all subsequent experiments (see below). Eosinophils were separated by percoll density gradients.
Figure 5. Eosinophil generation of ${ }^{\circ} \mathrm{O}_{2}^{-}$after inhibition of phospholipase $A_{2}$ by mepacrine. Incubation of human eosinophils $(n=$ five experiments) with mepacrine blocked the generation of ${ }^{\circ} \mathrm{O}_{2}^{-}$after stimulation with FMLP and CYB. ${ }^{*} P<0.002$ vs control. Some standard error bars are contained within the point symbols. Comparison is made at $100 \mu \mathrm{M}$ mepacrine as above. Eosinophils were separated by Percoll density gradients. 


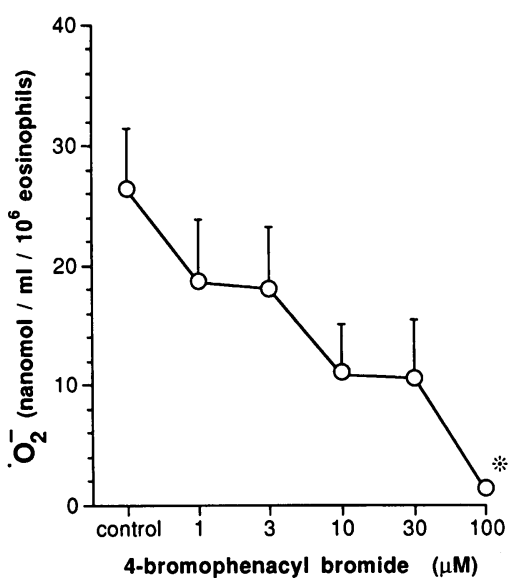

Reversal of mepacrine-induced inhibition of EPO release, $\mathrm{LTC}_{4}$ secretion, and ${ }^{\circ} \mathrm{O}_{2}^{-}$generation by arachidonic acid. To determine the specificity of mepacrine in inhibiting eosinophil degranulation and leukotriene production, experiments were performed measuring EPO release, $\mathrm{LTC}_{4}$ secretion, and ${ }^{\circ} \mathrm{O}_{2}^{-}$ generation in activated eosinophils after treatment with exogenous AA. Eosinophils in these experiments were isolated by immunomagnetic separation.

Treatment of eosinophils with AA reversed substantially the inhibitory effects of mepacrine on both degranulation and secretion of $\mathrm{LTC}_{4}$. In five experiments, eosinophils treated with both $100 \mu \mathrm{M}$ mepacrine and $1 \mu \mathrm{M}$ AA and then activated with FMLP and CYB released EPO at a concentration $10.4 \pm 2.2 \%$ total cell content vs $4.1 \pm 0.8 \%$ total cell content for eosinophils treated with mepacrine but not AA $(P<0.02)$ (Fig. 7). Treatment with $A A$ did not alter subsequent $E P O$ secretion caused by FMLP and CYB: EPO secretion after both AA and FMLP/CYB was $93.9 \pm 21.0 \%$ of secretion caused by FMLP/ CYB alone $(P=\mathrm{NS})$. Treatment with AA did not alter EPO release in nonactivated, quiescent eosinophils or cells treated with mepacrine (Table I).

In eight additional experiments, activation of eosinophils with FMLP + CYB caused $\mathrm{LTC}_{4}$ secretion of $1,125 \pm 527 \mathrm{pg} /$ $\mathrm{ml}$ per $10^{6}$ eosinophils after $30 \mathrm{~min}$, vs $44.2 \pm 24.0 \mathrm{pg} / \mathrm{ml} \mathrm{per}$ $10^{6}$ eosinophils after $30 \mathrm{~min}$ for nonactivated eosinophils $(P$ $<0.04$ ) (Fig. 1). Incubation with $100 \mu \mathrm{M}$ mepacrine before activation with FMLP + CYB almost completely inhibited $\mathrm{LTC}_{4}$ secretion $\left(68.2 \pm 32.2\right.$ vs $1,125 \pm 527 \mathrm{pg} / \mathrm{ml}$ per $10^{6}$ eosinophils, $P<0.04$ ) (Fig. 8). In eosinophils treated with $100 \mu \mathrm{M}$ mepacrine, incubation with $10 \mu \mathrm{M}$ AA before activation with FMLP + CYB restored $\mathrm{LTC}_{4}$ secretion to $695 \pm 413 \mathrm{pg} / \mathrm{ml}$ per $10^{6}$ eosinophils $(P<0.04$ vs activated eosinophils treated with mepacrine but not AA; $P=$ NS vs activated eosinophils not treated with mepacrine) (Fig. 8). Treatment with AA did not alter $\mathrm{LTC}_{4}$ secretion in nonactivated, quiescent eosinophils or cells treated with mepacrine (Table I).

Treatment of eosinophils with AA did not reverse the inhibition of ${ }^{\circ} \mathrm{O}_{2}^{-}$generation elicited by $100 \mu \mathrm{M}$ mepacrine. In three additional experiments, eosinophils pretreated with both 100 $\mu \mathrm{M}$ mepacrine and $10 \mu \mathrm{M} \mathrm{AA},{ }^{\circ} \mathrm{O}_{2}^{-}$generation 30 min after activation with FMLP + CYB was $1.7 \pm 1.1 \mathrm{nmol} / \mathrm{ml}$ per $10^{6}$

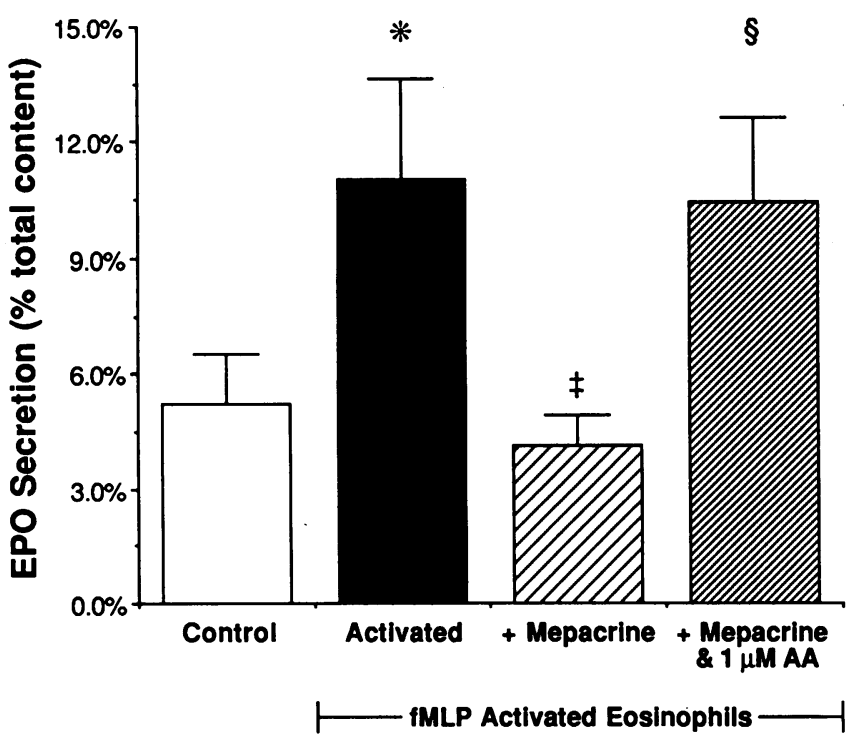

Figure 7. Reversal of mepacrine-induced inhibition of eosinophil secretion of EPO by AA. Incubation of human eosinophils ( $n=$ five experiments) with $1 \mu \mathrm{M} \mathrm{AA}$ after pretreatment with $100 \mu \mathrm{M}$ mepacrine reversed the inhibition of activated eosinophil EPO secretion noted with mepacrine alone. ${ }^{*} P<0.05$ vs control; ${ }^{\ddagger} P<0.02$ vs activated eosinophils; ${ }^{\S} P<0.02$ vs mepacrine-treated but not AA-treated eosinophils. Eosinophils were separated by immunomagnetic fractionation.

cells vs $1.4 \pm 0.8 \mathrm{nmol} / \mathrm{ml}$ per $10^{6}$ cells for activated eosinophils pretreated with mepacrine but not AA. Treatment of activated eosinophils with $10 \mu \mathrm{M}$ AA alone did not alter ${ }^{\circ} \mathrm{O}_{2}^{-}$generation, which after 30 min was $99.5 \pm 9.1 \%$ of activated eosinophils not treated with AA.

\section{Discussion}

These data demonstrate that blockade of endogenous phospholipase $\mathrm{A}_{2}$ causes inhibition of degranulation and release of EPO in activated human eosinophils. We found that eosinophil secretion of $\mathrm{LTC}_{4}$ and generation of ${ }^{\circ} \mathrm{O}_{2}^{-}$also was blocked by inhibition of endogenous PLA $\mathrm{PL}_{2}$. Both inhibition of EPO release and ${ }^{\circ} \mathrm{O}_{2}^{-}$generation by $\mathrm{PLA}_{2}$ blockade were dependent upon

Table I. Release of EPO and Secretion of LTC 4 by Nonactivated (Quiescent) Human Eosinophils after Incubation with $A A$ and Mepacrine

\begin{tabular}{lcc}
\hline \multicolumn{1}{c}{ Group } & EPO & LTC $_{4}$ \\
\hline & \% total content* & $p g /$ ml per $10^{\circ}$ cells \\
Control & $5.2 \pm 1.3^{*}$ & $44.2 \pm 24.0$ \\
Mepacrine alone & $3.5 \pm 0.6$ & $0.5 \pm 0.1$ \\
AA alone & $6.2 \pm 1.8$ & $3.0 \pm 0.6$ \\
Both mepacrine and AA & $5.3 \pm 1.0$ & $16.1 \pm 8.6$
\end{tabular}

Eosinophils were incubated with $100 \mu \mathrm{M}$ mepacrine fro $15 \mathrm{~min}$ followed by $1 \mu \mathrm{M}$ (for EPO experiments) or $10 \mu \mathrm{M}$ (for $\mathrm{LTC}_{4}$ experiments) AA for an additional $15 \mathrm{~min}$ at $37^{\circ} \mathrm{C}$ and compared to control eosinophils under same conditions. There are no differences in either EPO release or $\mathrm{LTC}_{4}$ secretion between groups. ${ }^{*} n=5$ for EPO experiments and 8 for $\mathrm{LTC}_{4}$ experiments. ${ }^{\ddagger}$ Values represent mean $\pm \mathrm{SE}$. 


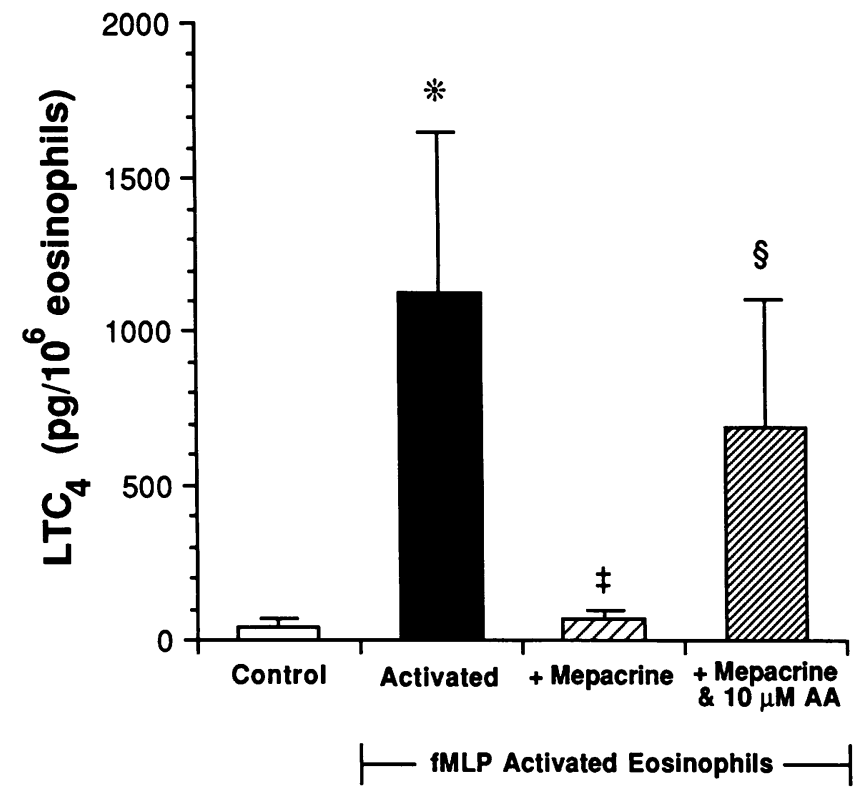

Figure 8. Eosinophil generation of $\mathrm{LTC}_{4}$ after inhibition of phospholipase $\mathrm{A}_{2}$ by mepacrine. Incubation of human eosinophils ( $n=$ eight experiments) with $100 \mu \mathrm{M}$ mepacrine blocked completely the secretion of $\mathrm{LTC}_{4}$ after activation with FMLP and CYB. Incubation with $10 \mu \mathrm{M}$ AA after mepacrine pretreatment and before activation significantly reversed the inhibitory effect of mepacrine. ${ }^{*} P<0.04$ vs control; ${ }^{\ddagger} P<0.04$ vs activated eosinophils; ${ }^{\S} P<0.04$ vs mepacrinetreated eosinophils. Eosinophils were separated by immunomagnetic fractionation.

the concentration of the PLA ${ }_{2}$ inhibitor. In these studies, inhibition of both EPO release and $\mathrm{LTC}_{4}$ secretion was reversed by addition of arachidonic acid. We demonstrate that endogenous $\mathrm{PLA}_{2}$ may regulate mediator secretion and degranulation in eosinophils.

Eosinophil activation and degranulation may be caused by a number of agents, such as platelet-activating factor, FMLP, and secretory immunoglobulin A (29-31). In these experiments, we used FMLP plus CYB as an activator for eosinophil degranulation. FMLP activates eosinophils by binding to specific membrane receptors (30), an action which is augmented substantially in the presence of CYB $(20,21)$. We have demonstrated previously that FMLP plus CYB causes eosinophil release of EPO that is measured readily in biologic fluids (20). Eosinophil peroxidase release and $\mathrm{LTC}_{4}$ secretion were readily elicited by FMLP plus CYB in our experiments (Fig. 1). Superoxide radical generation was less readily elicited in eosinophils isolated by immunomagnetic separation compared to Percoll separation (Fig. 1). In several experiments using eosinophils isolated by immunomagnetic separation, ${ }^{\circ} \mathrm{O}_{2}^{-}$generation was not substantially above baseline, and these experiments were excluded from analysis. Sufficient ${ }^{\circ} \mathrm{O}_{2}^{-}$was generated after eosinophil activation with FMLP and CYB in each series of experiments to determine the effects of both mepacrine and BPB (Figs. 5 and 6), and the effects of exogenous AA on inhibition elicited by mepacrine (see above).

Both mepacrine and BPB inhibited subsequent degranulation and ${ }^{\circ} \mathrm{O}_{2}^{-}$generation by activated eosinophils, and mepacrine inhibited subsequent $\mathrm{LTC}_{4}$ secretion. Each antagonist inhibits $\mathrm{PLA}_{2}$ by a distinct mechanism. Mepacrine inhibits $\mathrm{PLA}_{2}$ competitively either by direct interaction (17) or by formation of stable complexes of drug and phospholipid substrate (18). Bromophenacyl bromide inhibits PLA $_{2}$ noncompetitively by modification of an active site histidine residue (19). Concentrations and activity of endogenous eosinophil PLA $\mathrm{P}_{2}$ were not determined in this study. However, the similar actions of two specific agents with different modes of antagonism, and the bypass of the blockade of PLA $_{2}$ with exogenous arachidonic acid, suggest strongly that the inhibition of eosinophil activation and degranulation in these experiments is caused by inhibition of $\mathrm{PLA}_{2}$ and is not a nonspecific, cytotoxic effect of either mepacrine or BPB.

The inhibition of $\mathrm{PLA}_{2}$ elicited by mepacrine, and the subsequent inhibition of both EPO and $\mathrm{LTC}_{4}$ secretion, was reversed by treating eosinophils with AA before activation with FMLP. The concentrations of AA used, $1-10 \mu \mathrm{M}$, were sufficient to permit both EPO release and $\mathrm{LTC}_{4}$ secretion that was similar to that obtained by activated eosinophils not treated with mepacrine (Figs. 7 and 8 ). While pretreatment of eosinophils with either mepacrine or BPB blocked subsequent ${ }^{\circ} \mathrm{O}_{2}^{-}$ generation, treatment with AA did not reverse inhibition elicited by mepacrine and did not restore ${ }^{\circ} \mathrm{O}_{2}^{-}$generation after stimulation with FMLP + CYB. Phospholipase $A_{2}$ activity previously has been demonstrated in neutrophils (32-35) and causes release of eicosanoid mediators and ${ }^{\circ} \mathrm{O}_{2}^{-}(36-38)$; this can be blocked by either BPB (34) or mepacrine (35). Phospholipase $\mathrm{A}_{2}$ stimulates ${ }^{\circ} \mathrm{O}_{2}^{-}$generation in neutrophils by releasing AA which activates NADPH oxidase (38); ${ }^{\circ} \mathrm{O}_{2}^{-}$generation can be blocked by inhibition of $\mathrm{PLA}_{2}$ and restored by addition of exogenous AA. However, suppression of eicosanoid release and ${ }^{\circ} \mathrm{O}_{2}^{-}$generation by $\mathrm{PLA}_{2}$ inhibition in macrophages may be mutually independent (39). In the present study, while both EPO release and $\mathrm{LTC}_{4}$ secretion could be restored by addition of exogenous $\mathrm{AA}$, inhibition of ${ }^{\circ} \mathrm{O}_{2}^{-}$generation by mepacrine was not reversed by exogenous AA. These data suggest that eicosanoid production in eosinophils, as in neutrophils, depends upon activation of $\mathrm{PLA}_{2}$. Our data suggest further that in eosinophils, unlike neutrophils, ${ }^{\circ} \mathrm{O}_{2}^{-}$generation in eosinophils may not be linked to AA metabolism; however, we do not consider our data to be conclusive on this point.

Eosinophil peroxidase is a constituent of the matrix of cationic eosinophil granules $(1,27)$. This protein is synthesized during eosinopoiesis and are not further synthesized after release of the cell from the bone marrow $(40,41)$. Release of EPO and other eosinophil granular proteins involves solubilization of granular proteins into vacuoles followed by extrusion of the vacoular contents from the eosinophil into the surrounding environment (42). Therefore, determination of EPO concentrations in eosinophil-conditioned media is a marker for degranulation $(20,43)$. Eosinophil degranulation, and the inhibition of degranulation by mepacrine and BPB, were demonstrated consistently by this assay (Figs. 1, 3, 4, and 7).

In these studies, eosinophils were isolated in these experiments either by separation through discontinuous Percoll density gradients or by negative-selection immunomagnetic bead fractionation. The later method has been developed recently (22) and isolates eosinophils in greater number from equivalent volumes of blood compared with density gradient methods. Each method isolated eosinophils in sufficient purity ( $>92$ and $>98 \%$, respectively) to exclude substantial numbers of neutrophils. In these studies, both the purity of isolated cells 
and subsequent EPO release after incubation with FMLP + CYB by either method were comparable.

Phospholipase $\mathrm{A}_{2}$ can mediate a variety of actions within cells either directly or via subsequent transformation of its products: arachidonic acid metabolized into prostaglandins, leukotrienes, thromboxanes, and lipoxins; and lysophospholipids metabolized into platelet activating factor (44). Each of these lipid mediators has been implicated in a number of inflammatory processes and tissue injury, and many may have roles as second messenger (45). Phospholipase $A_{2}$ activation also can modify cell membrane dynamics. Phospholipid turnover in cell membranes may represent both replacement of oxidized phospholipids (46) and also reflect fundamental signalling mechanisms by which a cell respond to its environment (44, 45). We did not delineate which of these activities of PLA $\mathrm{A}_{2}$ was responsible for eosinophil degranulation and ${ }^{\circ} \mathrm{O}_{2}^{-}$generation.

In summary, we demonstrate that inhibition of endogenous eosinophil PLA $\mathrm{A}_{2}$ inhibits release of EPO, $\mathrm{LTC}_{4}$ secretion, and ${ }^{\circ} \mathrm{O}_{2}^{-}$generation from isolated, human eosinophils. Inhibition is specific to a product of the hydrolytic reaction catalyzed by $\mathrm{PLA}_{2}$ and can be reversed by addition of exogenous arachidonic acid. These data demonstrate the potential of PLA $\mathrm{A}_{2}$ to regulate eosinophil secretory activity that pertains to inflammatory states such as human asthma.

\section{Acknowledgments}

We thank Dr. Gerald J. Gleich, Professor of Medicine, Mayo Graduate School of Medicine, Rochester, MN, for the purified EPO used in these studies.

This work was supported by National Heart, Lung and Blood Institute grants HL-46368 and HL-32495, and by grants from the American Lung Association. Dr. White is a recipient of Clinical Investigator Award HL-02484 from the National Heart, Lung and Blood Institute, an Edward Livingston Trudeau Fellowship from the American Lung Association, and a fellowship award from the Schweppe Foundation. Dr. Strek is a recipient of grants from the Parker B. Francis Foundation and the Chicago Lung Association.

\section{References}

1. Hamann, K. J., and G. J. Gleich. 1990. Eosinophil structure and function: roles in host defense and pathogenesis of disease. In Local Immunity: Natural Resistance to Infection. Vol. 6. C. Sorg, editor. Gustav Fischer Verlag, New York. p. 60 .

2. Horn, B. R., E. D. Robin, J. Theodore, and A. van Kessel. 1975. Total eosinophil counts in the management of bronchial asthma. N. Engl. J. Med. 292:1152-1155.

3. Griffin, E., L. Håkansson, H. Formgren, K. Jörgensen, C. Peterson, and P. Venge. 1991. Blood eosinophil number and activity in relation to lung function in patients with asthma and with eosinophilia. J. Allergy Clin. Immunol. 87:548557.

4. Ädelroth, E., L. Rosenhall, S. Johansson, M. Linden, and P. Venge. 1990. Inflammatory cells and eosinophilic activity in asthmatics investigated by bronchoalveolar lavage. Am. Rev. Respir. Dis. 142:91-99.

5. Djukanovic, R., J. W. Wilson, K. M. Britten, S. J. Wilson, A. F. Walls, W. R. Roche, P. H. Howarth, and S. T. Holgate. 1990. Quantitation of mast cells and eosinophils in the bronchial mucosa of symptomatic atopic asthmatics and healthy control subjects using immunohistochemistry. Am. Rev. Respir. Dis. 142:863-871.

6. Kroegel, C., T. Yukawa, G. Dent, P. Chanez, K. F. Chung, and P. J. Barnes. 1988. Platelet-activating factor induces eosinophil peroxidase release from purified human eosinophils. Immunology. 64:559-562.

7. Owen, W. F., Jr., R. J. Soberman, T. Yoshimoto, A. L. Sheffer, R. A. Lewis, and K. F. Austen. 1987. Synthesis and release of leukotriene C4 by human eosinophils. J. Immunol. 138:532-538.

8. Hodges, M. K., P. F. Weller, N. P. Gerard, S. J. Ackerman, and J. M.
Drazen. 1988. Heterogeneity of leukotriene $\mathrm{C}_{4}$ production by eosinophils from asthmatic and from normal subjects. Am. Rev. Respir. Dis. 138:799-804.

9. Frigas, E., D. A. Loegering, and G. J. Gleich. 1980. Cytotoxic effects of the guinea pig eosinophil major basic protein on tracheal epithelium. Lab. Invest. 42:35-43.

10. White, S. R., S. Ohno, N. M. Munoz, G. J. Gleich, C. Abrahams, J. Solway, and A. R. Leff. 1990. Direct and augmenting effects on airway smooth muscle contraction from epithelial secretion elicited by the major basic protein of eosinophils. Am. J. Physiol. (Lung Cell Mol. Physiol.) 259:L294-303.

11. Motojima, S., E. Frigas, D. A. Loegering, and G. J. Gleich. 1989. Toxicity of eosinophil cationic proteins for guinea pig tracheal epithelium in vitro. $\mathrm{Am}$. Rev. Respir. Dis. 139:801-805.

12. Ayars, G. H., L. C. Altman, M. M. McManus, J. M. Agosti, C. Baker, D. L. Luchtel, D. A. Loegering, and G. J. Gleich. 1989. Injurious effect of the eosinophil peroxide-hydrogen peroxide-halide system and major basic protein on human nasal epithelium in vitro. Am. Rev. Respir. Dis. 140:125-131.

13. Van den Bosch, H., and Van Den Besselaar. 1978. Intracellular formation and removal of lysophospholipids. In Advances in Prostaglandin and Thromboxane Research. Vol. 3. C. Galli, G. Galli, and G. Porcellati, editors. Raven Press, Ltd., New York. p. 60.

14. Franson, R., S. Beckerdite, P. Wang, M. Waite, and P. Elsbach. 1973 Some properties of phospholipases of alveolar macrophages. Biochim. Biophys. Acta. 296:365-373.

15. Vadas, P., and W. Pruzanski. 1986. Role of secretory phospholipases $A_{2}$ in the pathobiology of disease. Lab. Invest. 55:391-404.

16. Bak, C. E. T., J. L. Checkel, G. J. Gleich, and D. W. Morgan. 1991. Phospholipase $\mathrm{A}_{2}$ identified in granular fraction of human eosinophils. FASEB (Fed. Am. Soc. Exp. Biol.) J. 5:892A. (Abstr.)

17. Vigo, C., G. P. Lewis, and P. J. Piper. 1980. Mechanisms of inhibition of phospholipase A . Biochem. Pharmacol. 29:623-627.

18. Jain, M. K., M. Streb, J. Rogers, and G. H. De Haas. 1984. Action of phospholipase $A_{2}$ on bilayers containing lysophosphatidylcholine analogs and the effect of inhibitors. Biochem. Pharmacol. 33:2541-2546.

19. Roberts, M., R. Deems, T. Mincey, and E. Dennis. 1977. Chemical modifcation of the histidine residue in phospholipase $A_{2}$ Naja naja naja: a case of half-life reactivity. J. Biol. Chem. 252:2405-2411.

20. White, S. R., G. V. P. Kulp, S. M. Spaethe, E. Van Alstyne, and A. R. Leff. 1991. A kinetic assay for eosinophil peroxidase activity in eosinophils and eosinophil conditioned media. J. Immunol. Methods. 144:257-263.

21. Shaw, R. J., O. Cromwell, and A. B. Kay. 1984. Preferential generation of leukotriene $\mathrm{C}_{4}$ by human eosinophils. Clin. Exp. Immunol. 56:716-722.

22. Verhagen, J., P. L. Bruynzeel, J. A. Koedam, G. A. Wassink, M. de Boer, G. K. Terpstra, J. Kreukniet, G. A. Veldink, and J. F. Vliegenthart. 1984. Specific leukotriene formation by purified human eosinophils and neutrophils. FEBS (Fed. Eur. Biochem. Soc.) Lett. 168:23-28.

23. Sedgwick, J. B., R. F. Vrtis, M. F. Gourley, and W. W. Busse. 1988. Stimulus-dependent differences in superoxide anion generation by normal human eosinophils and neutrophils. J. Allergy Clin. Immunol. 81:876-883.

24. Hansel, T. T., J. M. De Vries, I. Thomas, S. Rihs, M. Wandzilak, S. Betz, K. Blaser, and C. Walker. 1991. An improved immunomagnetic procedure for the isolation of highly purified human blood eosinophils. J. Immunol. Methods. 145:105-110.

25. Pick, E., and D. Mizel. 1981. Rapid microassays for the measurement of superoxide and hydrogen peroxide production by macrophages in culture using an automatic enzyme immunoassay reader. J. Immunol. Methods. 46:211-226.

26. Van Gelder, B. F., and E. C. Slater. 1962. The extinction coefficient of cytochrome c. Biochim. Biophys. Acta. 58:593-595.

27. Agosti, J. M., L. C. Altman, G. H. Ayars, D. A. Loegering, G. J. Gleich, and S. J. Klebanoff. 1987. The injurious effect of eosinophil peroxidase, hydrogen peroxide and halides on pneumocytes in vitro. J. Allergy Clin. Immunol. 79:496504.

28. Sachs, L. 1984. Applied Statistics. A Handbook of Techniques. SpringerVerlag New York Inc. 707 pp.

29. Kita, H., R. I. Abu-Ghazaleh, G. J. Gleich, and R. T. Abraham. 1991. Role of pertussis toxin-sensitive $G$ proteins in stimulus-dependent human eosinophil degranulation. J. Immunol. 147:3466-3473.

30. Kroegel, C., M. A. Giembycz, and P. J. Barnes. 1990. Characterization of eosinophil cell activation by peptides: differential effects of substance $P$, melittin, and fMET-Leu-Phe. J. Immunol. 145:2581-2587.

31. Abu-Ghazaleh, R. I., T. Fujisawa, J. Mestecky, R. A. Kyle, and G. J. Gleich. 1989. IgA-induced eosinophil degranulation. J. Immunol. 142:23932399.

32. Balsinde, J., E. Diez, A. Schuller, and F. Mollinedo. 1988. Phospholipase $A_{2}$ activity in resting and activated human neutrophils. Substrate specificity, $p H$ dependence, and subcellular localization. J. Biol. Chem. 263:1929-1936.

33. Bauldryl, S. A., R. L. Wykle, and D. A. Bass. 1988. Phospholipase $A_{2}$ activation in human neutrophils. Differential actions of diacylglycerols and alyklacylglycerols in priming cells for stimulation by n-formyl-met-leu-phe. J. Biol. Chem. 263:16787-16795. 
34. Duque, R. E., J. C. Fantone, C. Kramr, W. A. Marasco, and S. H. Phan. 1986. Inhibition of neutrophil activation by $\mathrm{p}$-bromophenacyl bromide and its effects on phospholipase A2. Br. J. Pharmacol. 88:463-472.

35. Taniguchi, K., M. Urakami, and K. Takanaka. 1988. Effects of various drugs on superoxide generation, arachidonic acid release and phospholipase $\mathrm{A}_{2}$ in polymorphonuclear leukocytes. Jpn. J. Pharmacol. 46:275-284.

36. Bomalaski, J. S., D. G. Baker, L. Brophy, N. V. Resurreccion, I. Spilberg, M. Muniain, and M. A. Clark. 1989. A phospholipase $A_{2}$-activating protein (PLAP) stimulates human neutrophil aggregation and release of lysosomal enzymes, superoxide and eicosanoids. J. Immunol. 142:3957-3962.

37. Daniels, R. H., M. J. Finnen, M. E. Hill, and J. M. Lackie. 1992. Recombinant human monocyte IL-8 primes NADPH-oxidase and phospholipase $\mathrm{A}_{2}$ activation in human neutrophils. Immunology. 75:157-163.

38. Henderson, L. M. J. B. Chappell, and O. T. G. Jones. 1989. Superoxide generation is inhibited by phospholipase $\mathrm{A}_{2}$ inhibitors. Role for phospholipase A2 in the activation of the NADPH oxidase. Biochem. J. 264:249-255.

39. Tsunawaki, S., and C. F. Nathan. 1986. Release of arachidonate and reduction of oxygen. Independent metabolic bursts of the mouse peritoneal macrophage. J. Biol. Chem. 261:11563-11570.
40. Lewis, D. M., J. C. Lewis, D. A. Loegering, and G. J. Gleich. 1978 Localization of the guinea pig eosinophil major basic protein to the core of the granule. J. Cell Biol. 77:701-713.

41. Hamann, K. J., R. L. Barker, R. M. Ten, and G. J. Gleich. 1991. The molecular biology of eosinophil granule proteins. Int. Arch. Allergy Appl. Immunol. 94:202-209.

42. Tai, P.-C., and C. J. F. Spry. 1981. The mechanisms which produce vacoulated and degranulated eosinophils. Br. J. Haematol. 49:219-226.

43. Fukuda, T., S. J. Ackerman, C. E. Reed, M. S. Peters, S. L. Dunnette, and G. J. Gleich. 1985. Calcium ionophore A23187 calcium-dependent cytolytic degranulation in human eosinophils. J. Immunol. 135:1349-1356.

44. Chang J., J. H. Musser, and H. McGregor. 1987. Phospholipase $A_{2}$ : function and pharmacological regulation. Biochem. Pharmacol. 36:2429-2436.

45. Dennis, E. A., S. G. Rhee, M. Billah, and Y. A. Hannun. 1991. Role of phospholipases in generating lipid second messengers in signal transduction. $F A$ SEB (Fed. Am. Soc. Exp. Biol.) J. 5:2068-2077.

46. Dawson, R. M. C. 1978. Enzymes metabolizing phospholipids: from infancy to middle age. Adv. Exp. Med. Biol. 101:1-13. 